\title{
Understanding the market for organic food
}

Associate Professor Stewart Lockie

Associate Dean (Research)

Faculty of Arts, Health and Sciences

Central Queensland University

Rockhampton QLD 4703, Australia

Phone: +61-7-49306539

Fax: +61-7-49306402

Email: s.lockie@cqu.edu.au

Dr Darren Halpin

Lecturer, Department of Economics and Public Policy

Robert Gordon University

Garthdee Road

Aberdeen AB10 7QE Scotland

Email: d.r.halpin@rgu.ac.uk

Dr David Pearson,

Lecturer, New England Business School

University of New England,

Armidale, NSW 2351, Australia

Email: dpearson@une.edu.au

Submitted to Organic Agriculture: A Global Perspective, CSIRO Publishing. Edited by Dr Paul Kristiansen, Professor Acram Taji and Professor John Reganold 


\section{Introduction}

By 2002, the international market in organic foods and beverages was estimated to be worth US $\$ 23$ billion (Sahota 2004). This brought the market share of certified organic food in the developed countries where it is predominantly consumed to somewhere between one and two percent of total food sales (Sligh and Christman 2003). According to critics, this small percentage proves organics to be little more than an overhyped Western food fad (see Lockie 2006, forthcoming). Yet with ongoing sales growth in developed countries of between eight and 20 percent, organic foods have attracted the interest of a growing number of farmers, food processing firms, retailers and governments (Burch et al 2001). Along with fair trade goods, organics has become one of the fastest growing sectors of a global food market characterised more generally by oversupply and falling terms of trade (McCoy and Parlevliet 2000; Raynolds 2000; Sligh and Christman 2003). Indeed, it has been estimated that the international market in organic foods could reach US\$100 billion as early as 2006 (McCoy and Parlevliet 2000) with the US organic sector alone worth over US $\$ 30$ billion by 2007 (Haumann 2004). From an insignificant niche market as recently as the mid-1990s (Sahota 2004), organics has, quite literally, exploded into the mainstream.

This is not to say that this growth will continue indefinitely. The expansion of European markets, in particular appears to slowing as they approach what some commentators refer to as 'maturity' (Sahota 2004). In other markets, such as Australia, the issue appears to be less one of demand slowing than of producers failing to supply produce of sufficient consistency in quantity and quality to secure a sound distribution and retail base (Conacher and Conacher 1991; Dumaresq and Greene 1997; Hassall 1990; Hudson 1996). This limits opportunities to sell certified organic produce as much as it reduces opportunities to purchase it! In fact, around 35 percent of certified organic produce grown in Australia is sold as conventional (Halpin 2004a). Compounding these demand and supply-side constraints on the continued expansion of the organic market is the simple issue that the organic industry knows little about who purchases its products or why they purchase them (Conacher and Conacher 1991; Dumaresq and Greene 1997; Hassall 1990; Hudson 1996).

Common lore tells us that organic market growth has been rooted in an unlikely mix of fear and fashion. Many consumers, it is believed, have been attracted to organics by their dread of the imperceptible threats of industrial food production. The BSE crisis and other food scares have so tested consumer confidence in conventional food systems, and the institutions that regulate them, it seems, that assurances regarding the safety of genetically-modified organisms, food irradiation and agricultural chemicals have fallen on deaf ears. Others, purportedly, have been attracted by the positioning of organics as a premium quality niche product. Substantially higher retail prices for organic foods have promoted a perception that they are consumed primarily by those wealthy enough to pay virtually any price to purchase what they believe to be tasty, safe or nutritious foods. There is certainly a grain of truth in these beliefs. However, research does show organic consumption to be somewhat more complicated. 
In this chapter, we examine the organic marketplace in terms of the changing dynamics of supply and demand; what currently is known about those who consume organic foods; what strategies have been set in place to recruit more people as organic food consumers; and constraints and opportunities for further expansion of the market for organic foods. In doing so, we will address, at least in part, one of the principal concerns that has arisen within the organic sector as a consequence of its growth; that is, the concern that expansion has come at the cost of the core values and practices on which organic agriculture was founded (see Chapters 9, 14, and Special Topic 3).

\section{The 'demand' for organic foods}

There is a widespread perception that rapid growth in the organic market since the mid1990s has been based more on an escalation of consumer demand than on an expansion of supply (Lyons 2001). This 'demand-pull' perspective on market growth is lent credence by the claims of a number of distributors, processors and retailers that they have experienced considerable difficulty sourcing enough certified produce to satisfy buyers, leading some to sponsor the conversion of conventional farmers to organic production (Halpin 2004b; Lyons 2001). Yet, as we have seen, there already are signs that recent rates of market expansion are slowing. The question is, at what point do we consider the market for organic produce to have 'matured'; that is, to have reached equilibrium of sorts between supply and demand that is likely to remain relatively steady for the short to medium term? Or to put it more bluntly, how big will the organic market get?

Demand, however, is a difficult concept to quantify. There are few people who, when asked, will state categorically that they would not purchase organic foods under any circumstances. In fact, surveys suggest that were organic foods to be made as widely available as conventional foods, almost all Western consumers would buy them at least some of the time (Lockie et al 2002). And the lower any retail price premium over outwardly similar conventional foods, not surprisingly, the more people express an interest in purchasing organic produce (Lockie and Donaghy 2004). The level of demand, therefore, for organic foods derives not only from the values, beliefs and socioeconomic status of food consumers, but on the relationship between these attributes and supply side issues such as quality, distribution and retail pricing. Levels of demand-even within markets that appeared to have reached maturity - may shift very rapidly in response to major changes in supply. Given these factors, we will examine demand, in this section, from the perspective of existing supply side dynamics, retail price premiums, and consumers' stated willingness to pay for certified organic foods.

Generating an accurate picture of the international organic sector accurately is hampered by limited data availability and uniformity. Nevertheless, the most recent International Federation of Organic Agriculture Movements (IFOAM) report suggests that of the US\$23 billion global retail market for organic food and drink in 2002, North America accounted for US $\$ 11.75$ billion, Europe US\$10.5 billion, Japan US $\$ 350$ million, Oceania 
US\$200 million, Latin America US\$100 million and the rest of Asia and the whole of Africa less than US $\$ 200$ million (Sahota 2004). These figures reflected growth, in 2002, of approximately 12 percent in North America, 8 percent in Europe, and 15-20 percent in Australia (Sahota 2004). Following several years of growth between 20 and 40 percent, the UK most exemplified the slowing of market expansion in those European countries with comparatively large organic markets (Sahota 2004). Importantly, if we compare this thumbnail sketch of the international organic marketplace with broad international patterns of organic production we find some notable points of divergence. Of the roughly 24 million hectares managed worldwide for certified organic production in 2002, over 10 million were located in Australia, 5.8 million in Latin America, 5.5 million in Europe, 1.5 million in North America, 880,000 in Asia, and 320,000 in Africa (Yussefi 2004). Despite the spatial dominance in Australia and Latin America of semi-arid rangelands used for extensive cattle grazing (Yussefi 2004), it is strikingly apparent that the poor countries of Africa, Asia and South America are producing significant quantities of organic foods almost exclusively for sale in Europe and North America (Parrott and Kalibwani 2004; Sligh and Christman 2003; Willer and Yussefi 2004). The same is true within Europe, where Italy and Spain act mostly as exporters to Germany and the UK (Smith and Marsden 2003), which import around 50 and 65 percent respectively of their organic food needs (Sligh and Christman 2003; see also McCoy and Parlevliet 2000).

Average national retail price premiums for certified organic food have been reported at 20-30 percent in Austria; 10-15 percent in Germany; 10-100 percent in both the US and UK; and 80 percent in Australia (Halpin and Brueckner 2004; Sligh and Christman 2003). Considerable variability also may be found both between commodities and within countries, with those products that are supplied in bulk, and widely distributed to consumers, tending to receive the smallest price premiums. This is the case for organic milk in both the EU-where retail premiums on milk are small to non-existent (Sligh and Christman 2003) - and Australia - where they are approximately 35 percent (Halpin and Brueckner 2004). In Denmark, where consumers display the second highest rate of expenditure on organic foods in Europe after Switzerland (Willer and Richter 2004), retail price premiums are reported to be negligible. The general pattern, however, is of retail premiums remaining considerably higher than the 15-20 percent that the majority of surveys suggest is acceptable to most Western consumers (Burfield 1998; Dabbert et al 2004; Lampkin 1990; Lockie et al 2002; Pearson 2001a; QDPI 2003). Even if we take on board Dabbert et al's (2004) suggestion that a retail premium of 25-30 percent is acceptable to enough European consumers that retailers may realistically charge this much while still broadening their organic customer base, existing retail premiums would seem a significant limitation on the ultimate size of the organic market.

Before concluding, however, that retail price premiums alone will ensure that organics never grows beyond its status as a lucrative niche market, a number of additional points must be considered:

- $\quad$ First, it is impossible to predict the impact that future events and technological developments will have on consumer trust, or distrust, in conventional food production and regulatory systems. Another 'BSE crisis' may well see perceptions regarding the acceptability of different price premiums revised upwards. 
Conversely, serious organic food scares may challenge perceptions that organic foods offer a safe alternative.

- $\quad$ Second, research by Donaghy et al (2003) suggests it is not the percentage increase in the price of individual organic foods that is important to most consumers but the absolute price increase. In other words, the majority of consumers may actually be willing to pay a higher premium, in percentage terms, for less expensive goods on the assumption that this will make little difference to their overall grocery bill. This leads to the rather obvious conclusion that the best way to maximise organic market share will be to reduce retail premiums on more expensive value-added items while concentrating more on improving the quality and supply of less expensive items. However, it must also be noted that organic foods often are represented, positioned and priced as premium gourmet brands - a strategy that Donaghy et al's research would suggest is likely to limit overall levels of demand.

- Third, changes in the retail structure of the organic industry are leading to major changes in the availability and cost of organic foods. While health food and specialist organic stores pioneered organic retailing, mainstream supermarkets now dominate the sector. This shift has contributed to lower retail price premiums and higher growth rates in the total market share of organic foods (Hamm et al 2002). But it appears also, in places, to have contributed to downward pressure on the prices received by farmers (Smith and Marsden 2003). This is likely to create, as Smith and Marsden (2003) point out, pressure to increase efficiency and economies of scale within the production sector in ways that may be inconsistent with organic values and principles. It is also likely to promote increased reliance on imports of organic food from lower cost production centres in Africa and South America (although, as Chapter 9 points out, producers in developing countries face substantial regulatory hurdles in exporting to lucrative Western markets).

- $\quad$ Fourth, in light of evidence that retail price premiums in general are substantially higher than those premiums received by farmers (Hassall and Associates 1996; Smith and Marsden 2003), it seems less than surprising that alternative marketing strategies based on direct farmer to consumer sales are developing alongside supermarket interest in organics. These promise to lower the gap between farm gate and retail premiums and suggest a range of possibilities for the resolution of supply problems and expansion of demand. The importance of retail strategy to the marketing of organic foods is explored in more detail in Section 4 below.

In sum, while there are plenty of signs that demand for organic foods will not support indefinite growth given existing retail price premiums, there also is evidence that innovations in distribution and retailing, coupled with lower retail price premiums, may provide the basis for continued expansion well beyond existing levels of organic food consumption.

\section{Why do people consume organic foods? Or not?}


International research suggests that those attributes of organic products most likely to influence consumers are, from most to least important, health (i.e. minimal artificial chemical residues in the product and high nutritional value), environment (i.e. environmentally friendly production and processing), taste, animal welfare, minimal processing, novelty, and fashion. Conversely, those attributes most likely to limit consumption of organics are identified, again, from most to least important, as high price, limited availability, skepticism about the credibility of product claims, poor appearance, no awareness of organic, and contentment with existing products (Beharrell and MacFie 1991; Davies et al 1997; Klonsky and Tourte 1998; Latacz-Lohmann and Foster 1997; Lockie et al 2002; Makatouni 2001; Magnusson et al 2001; Pearson 2001a, 2002).

According to Sahota (2004), the typical organic consumer is urban, well-educated, from a middle to high income household, and discerning in their food choices. US market researchers Hartman and Wright (1999) posit a more differentiated mix of organic consumers that includes: a small group of passionate environmentalists; an older, wealthier group concerned mostly about their own health; a young group who profess environmental concern but who tend to act on that concern only when convenient; and a growing mainstream who care about the environment and are willing to engage in 'green consumption' as products become more accessible. Both Sahota and Hartman and Wright's claims seem to make sense in light of the high retail premiums paid for organic foods. But it is important not to dismiss organic consumption as the domain only of the rich and passionate. According to Hartman and Wright (1999), the majority of those with no immediate interest in green consumption are those who struggle for economic survival - an underclass of the unemployed, underemployed, and underpaid. If this group of very poor are taken out of consideration for a moment, some 75 percent of US consumers emerge as genuinely interested in purchasing organic foods.

This is not surprising. The belief that food should be safe, nutritious, tasty and environmentally responsible is not radical or marginal. It should also come as no surprise, therefore, that large numbers of food consumers in Western countries profess to consume at least some organic food-40 percent in Australia (Lockie et al 2002). Consequently, several studies from around the world have found that beyond the exclusion of the very poor there are few meaningful demographic differences in Western countries between those people who consume organic foods and those who do not (Cunningham 2001; Davies et al 1997; Lockie et al 2002). The most important dimension of demographic difference is not education or income, as suggested by Sahota (2004), but gender, with significantly more women than men claiming to purchase organic foods (Cunningham 2001; Davies et al 1997; Lockie et al 2002). According to Cunningham (2001), this may stem from the higher levels of responsibility taken by women for feeding children and other family members although, as noted by Lockie et al (2005), such responsibility can also place pressure on women to prioritise convenience and price.

Of course, the reality is that while many Western consumers claim to consume organic foods - and many more profess the values that underpin organic agriculture - overall levels of organic food consumption remain only one to two percent of total food sales. This raises the questions as to just how many people purchase a substantial proportion of 
their food as organic and what it is that differentiates these committed organic consumers from more occasional organic consumers? For Australia, Lockie et al (2005) estimated that committed organic consumers - those who claimed to consume half or more of their diet as organic - accounted for approximately half of all certified organic food sales. This group were more motivated than were occasional organic consumers to source foods they believed were natural (ie. free from artificial additives, unnecessary processing, genetic engineering, irradiation, pesticides, preservatives, animal growth hormones and antibiotics), environmentally friendly, supportive of animal welfare, and likely to make them feel good emotionally. It is important to note, however, that these groups did not express fundamentally different food values. Even those who did not consume any organic foods claimed to be motivated in their food choices by health, environmental and animal welfare concerns. The difference among the groups was how strongly these motivations were expressed relative to price and convenience.

Lockie et al (2004) examined also the ways in which the motivations behind food choice interacted to influence increasing levels of organic food consumption. They found the major direct influence on increasing rates of organic food consumption to be consumers' commitment to the consumption of foods they perceived to be natural. Women, and those responsible for household food provisioning, were far more likely than others to be motivated by this concern. This was followed by willingness to pay a premium for environmental values. The next most important factor directly influencing rates of organic consumption was the level of motivation towards the consumption of food that made the respondent feel good, physically and emotionally. Organic food was not only believed to taste and smell better, but to evoke feelings of safety and tradition. Again, responsibility for household food provisioning and gender were the major determinants of consumers' level of motivation towards sensory and emotional appeal.

\section{Marketing organic foods}

One of the things that is truly remarkable about organic foods, given their status as one of the fastest growing sectors of the food industry, is how little their marketing depends either on consumer research or on aggressive advertising and discounting. At face value, the 'demand-pull' perspective on organic sector growth would suggest that organic growers have been in the enviable position of being able to concentrate their energies on expanding their farming operations while receiving premium prices for their produce. Despite a paucity of organic food advertising in the mainstream media, that media portrays organics as the almost sole alternative to environmental and food safety risks associated with industrial agriculture (see Lockie 2006, forthcoming). Analysis of newspaper references to organic food and agriculture in the UK, US and Australia suggests that the term 'organic' has come to signify a loosely defined bundle of desirable attributes related to quality, safety, ecology, tradition and provenance. In a world where regulatory agencies, and the complicated systems of quality assurance they administer, seem incapable of guaranteeing the safety of conventional foods, the organic label offers a simple, recognisable and, for some, comforting alternative (Lockie 2006, forthcoming). 
Unfortunately, for organic growers, organic produce does not necessarily 'walk off supermarket shelves'. The fact that a significant proportion of certified organic produce is still sold on conventional markets demonstrates there is no guarantee that the use of organic methods will result in the sale of a clearly differentiated organic product. As a consequence, marketing efforts within the organic production sector have concentrated on the development of supply chains (that is, on the development of distribution and retailing arrangements) and on the development of an appropriate regulatory regime to police usage of the term 'organic'.

We would argue that the single most important strategy in the marketing of organic foods has, in fact, been the establishment of regulatory systems to oversee the development of standards and inspection systems for organic production, processing and labelling (see Chapter 9). In terms of market expansion, independent third party certification of compliance with organic process standards achieves a number of things. Most obviously, certification provides some measure of guarantee for the buyer that they are getting what they pay for. As progress continues towards the harmonisation of standards on both national and international levels, buyers may extend their confidence to produce sourced from almost anywhere in the world. Further, even though no set of standards can be expected to codify adequately all the principles of organic agriculture, or all the conditions under which it might be practiced, compliance with these standards implies, nevertheless, an integrity that encourages consumers to associate a number of desirable attributes with certified organic foods even though, strictly speaking, those attributes fall outside the scope of what actually is guaranteed. Such attributes include taste, healthfulness, and so on. From the growers' perspective, independent certification enables those who have undertaken it to make claims that, in many circumstances, have clear value in the marketplace. The flipside to this, of course, is that the regulatory regimes underpinning certification preclude those who have not been certified from labelling their produce as organic.

Guthman (2004) argues that organic certification creates conditions of scarcity-by limiting the amount of food labelled as organic in the marketplace - and thus provides the basis for farm gate and retail price premiums. While notions of scarcity and price premiums intuitively would suggest that certification may limit market expansion, the effects may be both positive and negative. The cost and complexity of certification certainly does discriminate against smaller growers, particularly those in the developing world (see Chapter 9). However, scarcity and price premiums have acted to encourage those farmers and others who could afford the cost of certification into the organic sector and have thus helped to boost organic food supply and availability. This has been clearly demonstrated in the US where the implementation of a uniform national standard in 2002 is credited with boosting consumer awareness and confidence in organic produce and with clearing the way for its entry into mainstream supermarkets (Sahota 2004).

There are now few developed countries where mainstream supermarkets and other large retail chains do not appear set to dominate sales of organic foods. Among the world's three largest national organic markets, for example, supermarkets claimed 49 percent of organic retail sales in 2001-2002 in the US, 40 percent in Germany and 80 percent in the 
UK (Sligh and Christman 2003). Four years previously, the supermarket share of organic retail sales in Germany had been a mere 26 percent (Richter et al 2001). In the US, meanwhile, 31 percent of the organic retail market in 2001-2002 was held by just three natural food retail chains - Whole Foods Market, Trader Joe's and Wild Oats Marketsthat operated across multiple locations using store layouts and scales similar to those of conventional supermarkets (Sligh and Christman 2003). The increasing involvement of very large businesses, such as these, in the organic sector has, as indicated in the introduction to this chapter, attracted concern and criticism. The argument here is essentially that, in relatively small-scale and localised food networks, enough opportunities are afforded to consumers for direct interaction with growers to ensure their confidence in the integrity of the foods they purchase. By replacing direct interaction, and the trust it encourages, with codified sets of standards, the way is cleared for organic foods to be shipped around the world at enormous cost in fossil fuels and at the expense of values that are not easily codified such as agricultural biodiversity and community building (see Guthman 2004). The 'conventionalisation thesis', as this has become known, assumes that the entry of larger businesses into the organic sector: first, displaces the smaller businesses that pioneered the sector; and second, that these businesses do not share the values, nor implement organic standards with same authenticity, as organic pioneers.

There can be little doubt, however, that the increased visibility and availability of organics foods facilitated by mainstream supermarkets has played a major role in expansion of the organic market (Richter et al 2001). The reduced distribution costs and economies of scale enabled by the involvement of larger retailers have contributed to lower retail price premiums - and hence increased consumer demand - in those European countries where supermarkets dominate organic sales (Hamm et al 2002). Further, because the total volume of organic food sales has increased alongside mainstream supermarket involvement in the industry, the increased market share captured by supermarkets has not come directly at the cost of absolute sales among their competitors (Richter et al 2001). Indeed, where small retailers, such as health food stores, have experienced declining organic food sales they have done so less because of mainstream supermarket competition than because of competition from specialist organic and natural food chains (Richter et al 2001).

The other area of growth in organic food retailing (in absolute if not relative terms) has been direct farmer-consumer sales. Farmers' markets, box schemes, farm gate sales, community supported agriculture and other forms of direct selling accounted in 20012002 for 20 percent of organic retail sales in Germany, 16 percent in Australia, and 10 percent in Austria and Denmark (Sligh and Christman 2003; Lockie et al 2002). Similarly, direct sales accounted for 10 percent of all organic food sales in the UK in 2002-2003 (Soil Association 2003). Even in the US, where only 3 percent of organic retail sales were direct in 2001-2002 (Sligh and Christman 2003), thousands of farms are now involved in community supported agriculture programs that encourage tens of thousands of consumers to subscribe for a weekly share of the season's harvest, whatever it may bring (Pretty 2002). In contrast with the downward pressure that mainstream retailer involvement in organics is likely to place, in the longer term, on farm gate 
premiums (Smith and Marsden 2003), direct sales offer practical ways for farmers to capture a greater share of the consumer dollar. The emphasis placed by direct sales strategies on personal interaction, localisation and seasonality makes them particularly well suited to smaller growers who struggle to offer the quantities and continuity of supply required by supermarkets. At the same time, the emphasis placed by direct sales on personal interaction, localisation and seasonality promotes a sense of integrity and credibility in the organic sector. Altogether, this suggests that the relationship between large retailer involvement in organics and direct farmer-consumer sales is not always an antagonistic one. It is true that many of the people whom engage in direct sales, either as buyers or sellers, probably do so out of a belief that buying organic food at a chain store is somehow counter to the principles of organics. But it is also true: first, that many people who prefer to buy direct when possible still appreciate the convenience and accessibility of major retail chains when it is not (Lockie 2002); second, that many involved in direct sales as consumers came to an awareness of organics through the appearance of organic foods in conventional retailers; and third, that many small to medium size farms engage in both direct and indirect sales in order to spread their marketing options and risk (Halpin 2004a).

The importance of large mainstream retailers and the visibility they lend to organics is underscored by Richter et al's (2001) review of organic food marketing in Europe and the US. The most important feature of those supermarket chains that reported success in their marketing of organic products - in terms of profitability and corporate image - was the in-store visibility of organic products. This visibility was underscored by the range of organic products available, the availability of promotional and educational material within the store, and knowledgeable sales people. These chains took active steps to ensure that, wherever possible, every major product grouping included a high quality organic option by appointing dedicated senior management personnel and by working with suppliers. It also was evident that the leading chains in organic sales had been involved in the sector since before demand for organic products mushroomed in the late 1990s (suggesting they were key players in this escalation of demand), had detailed environmental management policies and strategies that extended beyond the sale of organic foods to include matters such as energy conservation (see also Burch et al 2001), and featured organics prominently in their advertising. Those chains less committed to organics tended to stocked a limited range of long shelf life dry goods. Almost all chains used their own organic certification labels to reduce confusion, although few collected data on who was buying their organic products or why. Consequently, there were few attempts to target the specific needs of different consumer groups and a general concentration on information related to health and food safety as well as, to a lesser extent, environment, taste and animal welfare (see also Hamm et al 2002).

\section{Expanding the 'market' for organic foods}

The foregoing discussion has highlighted a number of options for promoting continued expansion in the organic market. Consumer surveys from around the world consistently 
indicate both that the majority of Western consumers are positively disposed towards organic foods and that the major barriers to their increased consumption of those foods are perceived to be their price and availability. The experience of major retailers in Europe is consistent with these claims (Richter et al 2001). Those countries with comparatively more mainstream retailer involvement in the organic sector and/or lower retail premiums tend to have higher per capita levels of organic food consumption. At the same time, those retailers that report the most corporate benefit from organic sales are those that offer a comprehensive choice of easily identifiable organic product lines. Consumer research also highlights the importance of credibility and trust (see Lockie et al 2002), matters that increasingly are addressed though the implementation of strictly regulated standards setting and inspection regimes.

As stated above, we have no wish to imply here that all organic producers or processors need to do is get a certified product to market and it will sell itself. While there is insufficient space here to discuss the issue at length, we would suggest that one of the characteristics common to many growers, processors and retailers who successfully have expanded their sales is the considerable effort they have put into supply chain organisation (see Halpin 2004c). The key point here is that resolving the supply-side issues necessary to promote market expansion involves more than simply expanding production or putting more product lines on the shelf. For supermarkets that trade on convenience and choice, the focus of coordination is on securing supplies of consistent quality and quantity across a diverse product range. Strategies to achieve this range from supporting the conversion of conventional enterprises to organic production and processing, to encouraging the pooling of produce from smaller farms into larger consignments, and importing supplies from elsewhere. Even farmers' markets, community supported agriculture and box schemes that trade on seasonality, locality and community may be seen as methods to introduce convenience and choice to the realm of direct sales by making it easier for consumers to access a wider range of produce. Organisers of such schemes often supply recipes and other information to help consumers cope with the 'inconvenience' of seasonal gluts and shortages and with unfamiliar produce.

Of course, as important as supply chain organisation and standards regulation are to the organic market, we cannot overlook the questions of how organic foods and promoted and to whom. We know that organic foods are consumed in at least small quantities by enough Western consumers that there is little to differentiate between those who do eat organic food and those who do not (Pearson 2002). The values that underpin organic food and agriculture - environmental sustainability, food safety and nutrition, animal welfare, and so on - are widely perceived as important (Lockie et al 2002). Nevertheless, the most committed consumers of organic food are those who place a high value on the perceived naturalness of food (Lockie et al 2004). These are more likely to be women than men, and more likely than not to take major responsibility for food shopping and preparation within their household. This group do not need to be convinced of the merits of organic foods. Further, even though the demands placed on their time by responsibility for food provisioning lead this group to place a high value on convenience (Lockie et al 2004), this is the group most likely to actively seek out organic foods out and to adapt their 
shopping behaviour accordingly. In doing so, members of this group may challenge the idea that large supermarkets are as convenient as they are widely perceived to be and the notion that taking time to think about food is an inconvenience (Lockie 2002). In promoting organic foods to this group, the key attributes are naturalness and authenticity. They are uncomfortable with highly processed organic foods and long distance transportation and would rather know where they can buy fresh local produce and minimally processed dry goods.

The majority of organic food consumers are not, of course, so committed. They do not change their shopping habits readily and will substitute conventional products for organic whenever the latter are not available or affordable at their regular shopping outlets. Nevertheless, increasing sales to this group may represent one of the easier growth paths for the organic industry. These buyers do not need to be convinced of the merits of organic food. They already purchase it. All that needs to be done is to convince them to purchase more of it. In order to promote organic products to this group the organic industry needs to address a range of issues including:

- $\quad$ Pricing - retail price premiums remain considerably higher in most national markets than the majority of consumers are willing to pay. Addressing this will remove a major barrier to organic food sales among less committed consumers.

- Visibility - the majority of food purchasing decisions are based on habit (Pearson 2000). Varying habitual patterns and developing new shopping habits is strongly influenced by the visibility of alternatives. While introducing organic foods to major retail chains certainly has increased their visibility, the appearance and layout of product displays also is critical. The most influential area to display products is where buyers enter the retail outlet, at the ends of aisles, and/or at eye level. Even where this is not possible, it is important that displays identify organic products in some prominent manner.

- Labelling - as well as reducing the visibility of organic foods, inconsistent and inadequate labelling reduces consumer confidence and trust in the integrity of organic claims (Lockie et al 2002). National and international harmonisation or certified organic labels would be welcomed by the majority of consumers if not by the certifying bodies who compete for farmers' business.

- Availability - the supply and quality of organic products must be consistent enough that buyers are not tempted to substitute them for conventional products. There may be circumstances in which the organic industry is better served by a strategy of targeting a small number of key products than by attempting to provide a complete product range. Research has shown, for example, that a small number of fresh fruit and vegetables account for the majority of expenditure, suggesting that the organic industry could have the greatest impact on its overall sales by targeting the topselling items (Pearson 2000).

As stated above, there are relatively few Western consumers who state that they would not, under any circumstances, buy organic food. The barriers raised against organic consumption by members of this group typically focus, again, on pricing and availability (Pearson 2002). This group is clearly the least likely to bypass major retailers and make use of specialty food stores, home delivery services and so on. Given this, an obvious 
strategy to encourage members of this group to purchase organic foods is to sell them at the same price as conventional foods. At least one British supermarket chain has done this - selling some organic products at below cost - in order to increase the profile of its concern for the environment (Hutchins and Greenhalgh 1995). However, it is likely also that many strictly conventional food consumers see little intrinsic value in the organic label and are unlikely to purchase any organic food that does not possess the same visible quality attributes as conventional competitors (visual appearance, smell etc) even if it is no more expensive. This suggests that it is necessary to promote to this group the benefits of organic products, a strategy that may encourage them to accept a higher price because they believe that the positive attributes of organic products - health, taste, and environment-increase its value.

\section{Conclusion}

In this chapter, we deliberately have avoided offering a firm conclusion on just how big the organic market will grow. On the one hand, slowing rates of expansion in Europe may suggest that projections the organic market could reach US $\$ 100$ billion by 2006 are unduly optimistic, and that global demand for organic foods may plateau well before we reach this mark. On the other hand, few have so far tried to assess the implications of growing middle classes outside the developed economies of Europe, North America, Japan and Australia/New Zealand. Further, there is considerable scope still through adaptations in production, distribution and retailing strategies, and through the manipulation of retail price premiums, to influence demand in the West. In fact, the organic industry must, at some point, confront the question as to whether it wants to grow beyond a market share that enables it be dismissed as a niche market and whether it is prepared to take the steps necessary to support higher levels of demand. For some, quite legitimately, the answer will be no. For others, there will be no question that if environmentally sound agricultural practices are to become the norm there is no choice but to promote aggressive expansion in the organic sector. However, it cannot be taken for granted that the spectacular growth we have seen in the organic market over the last decade will continue indefinitely. Neither can it be taken for granted that the strategies which have underpinned that growth to date will be sufficient even to ensure the social and economic sustainability of the organic sector as it now stands.

The most obvious way to increase demand for organic foods is to lower retail price premiums. Improving the visibility, availability and labelling of organic foods also carries considerable potential. Achieving these will depend not just on an expansion of production but on the organisation of a range of supply chain arrangements to move organic foods from the field to the point of sale as clearly differentiated products. Some of these arrangements will be highly integrated national and international networks. Others will be highly localised and, at times, informal. We have argued in this chapter that while concern regarding the potential loss of key organic values and principles alongside market expansion is justified, it must also be recognised that the entry of mainstream retailers and other businesses into the organic sector has created 
opportunities for smaller enterprises and supply chains. This may not always be the case, but at the present time it does appear that the increased market share of large retailers has come from the increased demand that they have stimulated and not from the transfer of sales from elsewhere.

In closing, we would reiterate the point that underlies concern about 'conventionalisation'; that is, that organic foods must retain their integrity and authenticity if they are to maintain any economic value. As loosely defined as concepts of integrity and authenticity might be, it has been the ability of organic foods to signify a variety of often intangible attributes related to quality, safety, ecology, tradition and provenance that has provided the organic industry with the free advertising afforded its status as the main alternative to industrial agriculture - and all the risks and uncertainties with which this is attributed. If the market for organic food is to continue to grow it must continue to offer-from standards to supermarket shelves to farmers' markets - the taste, smell and texture of authenticity.

\section{References}

Beharrell, B. and MacFie, J. (1991) Consumer attitudes to organic foods, British Food Journal, 93, 25-30.

Burch, D., K. Lyons and G. Lawrence (2001) 'What do we mean by "green"? Consumers, agriculture and the food industry', in S. Lockie and B. Pritchard (eds) Consuming Foods, Sustaining Environments, Brisbane: Australian Academic Press.

Burfield, T. (1998) Organic impact, Healthy lifestyles (a supplement to Produce Merchandising), Vance Publishing, Lincolnshire, Illinios, USA, H3-H6

Conacher, J. and Conacher, A. (1991) An update on organic farming and the development of the organic industry in Australia, Biological Agriculture and Horticulture, 8, 1-16.

Cunningham, R. (2001) The organic consumer profile: Not only who you think it is! (Alberta: Strategic Information Services Unit, Agriculture, Food and Rural Development)

Davies, A., Titterington, A. and Cochrane, C. (1997) Who buys organic food? A profile of the purchasers of organic food in Northern Ireland, British Food Journal, 97, 17-23.

Dumaresq, D. and Greene, R. (1997) From farmer to consumer: The future of organic agriculture in Australia, Rural Industries Research and Development Corporation, Canberra, Australia.

Grunert, S. and Kristensen, K. (1991) In Enhancing consumer choice: Proceedings of the second international conference of research in the consumer interest, American Council of Consumer Interests (Ed, Mayer, R.) Columbia, Missouri, USA, 37-48.

Guthman, J. (2004) Agrarian Dreams. The Paradox of Organic Farming in California. Berkeley: University of California Press. 
Halpin, D. (2004a) 'A farm level view of the Australian organic industry', in Halpin, D. (ed) Australian Organic Industry Profile. Department of Agriculture, Fisheries and Forestry, Canberra.

Halpin, D. (2004b) 'Beyond the farm gate: the perspectives of processors, wholesalers and distributors in the organic industry', in Halpin, D. (ed) Australian Organic Industry Profile. Department of Agriculture, Fisheries and Forestry, Canberra.

Halpin, D. (2004c) 'Organic food supply chains and collaborative marketing', in Halpin, D. (ed) Australian Organic Industry Profile. Department of Agriculture, Fisheries and Forestry, Canberra.

Halpin, D. and Brueckner (2004) 'The retail pricing, labelling and promotion of organic food in Australia', in Halpin, D. (ed) Australian Organic Industry Profile. Department of Agriculture, Fisheries and Forestry, Canberra.

Hamm, U., Gronefeld, F. and Halpin, D. (2002) Analysis of the European market for organic food. Organic Marketing Initiatives and Rural Development 1. School of Management and Business, University of Wales, Aberystwyth, UK.

Hartman, H. and Wright, D. (1999) Marketing to the new wellness consumer: Understanding trends in wellness, $1^{\text {st }}$ edn, (Bellevue, Washington: The Hartman Group)

Hassall (1990) The market for Australian produced organic food, Rural Industries Research and Development Corporation, Canberra, Australia.

Hudson, R. (1996) The domestic market for Australian organic produce - an update, Rural Industries Research and Development Corporation, Canberra, Australia.

Hutchins, R. and Greenhalgh, L. (1995) Organic confusion: Sustaining competitive advantage, Nutrition \& Food Science, November/December, 11-4.

Klonsky, K. and Tourte, L. (1998) Organic agricultural production in the United States: Debates and directions, American Journal of Agricultural Economics, 80, 111924.

Lampkin, N. (1990) Organic farming, Farming Press, Ispwich, United Kingdom.

Latacz-Lohmann, U. and Foster, C. (1997) From "niche" to "mainstream" - strategies for marketing food in Germany and the UK, British Food Journal, 99, 275-82.

Lockie, S. (2002) “"The Invisible Mouth”: Mobilizing 'the Consumer' in Food Production-Consumption Networks', Sociologia Ruralis, 42(4), 278-294.

Lockie, S. and Donaghy, P. (2004) 'Who Consumes Organic Foods in Australia', in Halpin, D. (ed) Australian Organic Industry Profile. Department of Agriculture, Fisheries and Forestry, Canberra.

Lockie, S., Lyons, K., Lawrence, G. and Grice, J. (2004) 'Choosing Organics: A Path Analysis of Factors Underlying the Selection of Organic Food Among Australian Consumers', Appetite, 43, 135-146

Lockie, S., Lyons, K., Lawrence, G. and Mummery, K. (2002) 'Eating Green: Motivations Behind Organic Food Consumption in Australia', Sociologia Ruralis, 42(1), 20-37.

Lockie, S. (2006, forthcoming) 'Capturing the Sustainability Agenda: Organic Foods and Media Discourses on Food Scares, Environment, Genetic Engineering and Health', Agriculture and Human Values. 
Lyons, K. (2001) From sandals to suits: green consumers and the institutionalisation of organic agriculture. In Lockie, S. and Pritchard, B. (eds) Consuming foods, sustaining environments. Australian Academic Press: Brisbane.

Makatouni, A. (2001) What motivates consumers to buy organic food in the UK? Results from a qualitative study. organic-research.com 1 pp. 1-11.

Magnusson, M., Arvola, A., Koivisto Hursti, U., Aberg, L. and Sjoden, P. (2001) Attitudes towards organic foods among Swedish consumers, British Food Journal, 103, 209-26.

Marshall, A. (1998) In Fresh 98 National conference for the fresh fruit and vegetable industry. Organised by Australian United Fresh Fruit and Vegetable Association and Australian Horticultural Corporation. Hilton Hotel, Sydney, 1-8.

McCoy, S. and Parlevliet, G. (2000) Export market potential for clean and organic agricultural products. Rural Industries Research and Development Corporation: Canberra.

Pearson, D. (2000) Fresh fruits and vegetables: What we buy and why?, Food Australia, $52,306-8$.

Pearson, D. (2001a) How to increase organic food sales: Results from research based on market segmentation and product attributes, Australian Agribusiness Review, 9, 18.

Pearson, D. (2001b) Organic fresh fruits and vegetables: Buyer's selection of retail outlet and evaluation of individual products. PhD Thesis, University of New England, Armidale, NSW, Australia.

Pearson, D. (2002) Marketing organic food: Who buys it and what do they purchase?, Food Australia, 54, 31-4.

Pretty, J. (2002) Agri-Culture: Reconnecting People, Land and Nature, Earthscan, London.

Richter, T., Schmid, O., Meier, U., Halpin, D., van den Berge, P. and Damary, P. (2001) Marketing Approaches for Organic Products in Supermarkets: Case Studies from Western Europe and the United States of America conducted in 2000. Research Institute of Organic Agriculture: Ackerstrasse.

Sahota, A. (2004) 'Overview of the global market for organic food and drink' in $\mathrm{H}$. Willer and M. Yussefi (eds) The World of Organic Agriculture: Statistics and Emerging Trends, Bonn: International Federation of Organic Agriculture Movements.

Segger, P. (1997) World trade in organic foods: A growing reality. Paper presented at the Future Agenda for Organic Trade, Fifth IFOAM Conference on Trade in Organic Products, Oxford.

Sligh, M. and Christman, C. (2003) Who Owns Organic? The Global Status, Prospects and Challenges of a Changing Organic Market, Pittsboro, NC: Rural Advancement Foundation International — USA.

Soil Association (2003) Organic food and farming report 2003. Soil Association: Bristol. Thompson, G. (1998) Consumer demand for organic foods: What we know and what we need to know, American Journal of Agricultural Economics, 80, 1113-8. 